\title{
Nonlinear contractions and fixed point theorems with modified $\omega$-distance mappings in complete quasi metric spaces
}

\author{
Inam Nuseira,*, Wasfi Shatanawi ${ }^{\mathrm{b}, \mathrm{c}}$, Issam Abu-Irwaq ${ }^{\mathrm{a}}$, Anwar Bataihah ${ }^{\mathrm{d}}$ \\ ${ }^{a}$ Department of Mathematics and Statistics, Jordan University of Science and Technology, P. O. Box 3030, Irbid 22110, Jordan. \\ ${ }^{b}$ Department of Mathematics and General Courses, Prince Sultan University, Riyadh, Saudi Arabia. \\ ${ }^{c}$ Department of Mathematics, Hashemite University, P. O. Box 150459, Zarqa, Jordan. \\ ${ }^{d}$ Department of Mathematics, The University of Jordan, Amman, Jordan.
}

Communicated by M. S. Noorani

\begin{abstract}
Alegre and Marin [C. Alegre, J. Marin, Topol. Appl., 203 (2016), 32-41] introduced the concept of modified $\omega$-distance mappings on a complete quasi metric space in which they studied some fixed point results. In this manuscript, we prove some fixed point results of nonlinear contraction conditions through modified $\omega$-distance mapping on a complete quasi metric space in sense of Alegre and Marin. (c)2017 All rights reserved.
\end{abstract}

Keywords: Quasi metric, fixed point theorem, nonlinear contraction, altering distance, modified $\omega$-distance. 2010 MSC: 54H25, 47H09.

\section{Introduction}

The Banach contraction principle is one of the main results in fixed point theory, which asserts that every contraction in a complete metric space has a unique fixed point. Subsequently, a large number of generalizations of Banach's contraction theorem is obtained by many authors. For more details we refer the readers to $[1-4,7-11,16-19,21]$.

A self-mapping $T$ on a metric space $(X, d)$ is called Kannan contraction if there is a $k \in\left[0, \frac{1}{2}\right)$ such that

$$
d(T x, T y) \leqslant k[d(x, T x)+d(y, T y)], \quad \forall x, y \in X .
$$

Kannan [14] proved that every Kannan contraction in a complete metric space has a unique fixed point. It is worth mentioning that Kannans theorem is an important result since it characterizes the metric completeness (see [20]).

The concept of quasi metric spaces was introduced by Wilson [22].

\footnotetext{
*Corresponding author

Email addresses: imnuseir@just.edu.jo (Inam Nuseir), wshatanawi@psu.edu.sa (Wasfi Shatanawi), swasfi@hu.edu.jo (Wasfi Shatanawi), imabuirwaq@just.edu.jo (Issam Abu-Irwaq), anwerbataihah@gmail.com (Anwar Bataihah)
}

doi:10.22436/jnsa.010.10.20 
Definition 1.1 ([22]). Let $X$ be a nonempty set and $d: X \times X \rightarrow[0, \infty)$ be a given function which satisfies

(1) $d(x, y)=0$ if and only if $x=y$;

(2) $d(x, y) \leqslant d(x, z)+d(z, y)$ for any points $x, y, z \in X$.

Then $d$ is called a quasi metric on $X$ and the pair $(X, d)$ is called a quasi metric space.

It is clear that every metric space is a quasi metric space, but the reverse is not necessarily true.

A quasi metric $d$ induces a metric $d_{m}$ as follows:

$$
d_{m}(x, y)=\max \{d(x, y), d(y, x)\}
$$

The convergence and completeness in a quasi-metric space are defined as follows.

Definition $1.2([13])$. Let $(X, d)$ be a quasi-metric space, $\left(x_{n}\right)$ be a sequence in $X$, and $X \in X$. Then the sequence $\left(x_{n}\right)$ converges to $x$ if $\lim _{n \rightarrow \infty} d\left(x_{n}, x\right)=\lim _{n \rightarrow \infty} d\left(x, x_{n}\right)=0$.

Definition 1.3 ([13]). Let $(X, d)$ be a quasi-metric space and $\left(x_{n}\right)$ be a sequence in $X$. Then

(1) We say that the sequence $\left(x_{n}\right)$ is left-Cauchy if for every $\epsilon>0$, there is a positive integer $N=N(\epsilon)$ such that $d\left(x_{n}, x_{m}\right) \leqslant \epsilon$ for all $n \geqslant m>N$.

(2) We say that the sequence $\left(x_{n}\right)$ is right-Cauchy if for every $\epsilon>0$ there is a positive integer $N=N(\epsilon)$ such that $d\left(x_{n}, x_{m}\right) \leqslant \epsilon$ for all $m \geqslant n>N$.

Definition $1.4([13])$. Let $(X, d)$ be a quasi-metric space and $\left(x_{n}\right)$ be a sequence in $X$. We say that the sequence $\left(x_{n}\right)$ is Cauchy if for every $\epsilon>0$ there is positive integer $N=N(\epsilon)$ such that $d\left(x_{n}, x_{m}\right) \leqslant \epsilon$ for all $m, n>N$; that is $\left(x_{n}\right)$ is a Cauchy sequence if and only if it is left and right Cauchy.

Definition 1.5 ([13]). Let $(X, d)$ be a quasi-metric space. We say that

(1) $(X, d)$ is left-complete if every left-Cauchy sequence in $X$ is convergent;

(2) $(X, d)$ is right-complete if every right-Cauchy sequence in $X$ is convergent;

(3) $(X, d)$ is complete if every Cauchy sequence in $X$ is convergent.

A modified $\omega$-distance (shortly m $\omega$-distance) mapping on quasi metric space is given by Alegre and Marin [5] as follows.

Definition $1.6([5])$. A m $\omega$-distance on a quasi metric space $(X, d)$ is a function $q: X \times X \rightarrow[0, \infty)$ satisfying the following conditions:

(W1) $q(x, y) \leqslant q(x, z)+q(z, y)$ for all $x, y, z \in X$;

(W2) $\mathrm{q}(x,):. X \rightarrow[0, \infty)$ is lower semi-continuous for all $x \in X$;

(mW3) for each $\epsilon>0$ there is $\delta>0$ such that if $q(y, x) \leqslant \delta$ and $q(x, z) \leqslant \delta$ then $d(y, z) \leqslant \epsilon$.

Definition 1.7 ([5]). A strong m $\omega$-distance on a quasi metric space $(X, d)$ is a mw-distance $q: X \times X \rightarrow$ $[0, \infty)$ satisfying the following condition:

(mW2) $\mathrm{q}(., \mathrm{x}): X \rightarrow[0, \infty)$ is lower semi-continuous for all $x \in X$.

Remark 1.8 ([5]).

1. Every quasi metric $d$ on $X$ is an m $\omega$-distance on the quasi metric space $(X, d)$.

2. In general, a quasi metric $d$ on $X$ need not to be a strong mw-distance on the quasi metric space $(X, d)$.

For more details on mw-distance, we refer the readers to [5] and references therein. 
Definition 1.9 ([15]). The function $\varphi:[0, \infty) \rightarrow[0, \infty)$ is called an altering distance function if the following properties are satisfied:

(1) $\varphi$ is continuous and nondecreasing function;

(2) $\varphi(t)=0$ if and only if $t=0$.

Henceforth, we denote the class of all altering distance functions by $\Psi$.

Definition 1.10 ([12]). Let $S$ be the class of all functions $\alpha: \mathbb{R}^{+} \rightarrow[0,1)$ that satisfies the following implication

$$
\alpha\left(t_{n}\right) \rightarrow 1 \Longrightarrow t_{n} \rightarrow 0
$$

Geraghty in [12] proved the following fixed point result.

Theorem 1.11. Let $(X, d)$ be a complete metric space and $\mathrm{T}: \mathrm{X} \rightarrow \mathrm{X}$. Let $\alpha \in S$ such that

$$
d(T x, T y) \leqslant \alpha(d(x, y)) d(x, y), \quad \forall x, y \in X
$$

Then T has a unique fixed point.

Recently Amini-Harandi and Emami characterized Geraghty's theorem in the setting of partially ordered metric spaces as follows.

Theorem $1.12([6])$. Let $(\mathrm{X}, \mathrm{d}, \preceq)$ be a partially ordered complete metric space. Let $\mathrm{T}: \mathrm{X} \rightarrow \mathrm{X}$ be an increasing mapping such that there is $\mathrm{x}_{0} \in \mathrm{X}$ with $\mathrm{x}_{0} \preceq \mathrm{T} \mathrm{x}_{0}$. Suppose that there is $\alpha \in S$ such that

$$
d(T x, T y) \leqslant \alpha(d(x, y)) d(x, y)
$$

for all $x, y \in X$ with $x \succeq y$. Assume that either $T$ is continuous or $X$ is such that if an increasing sequence $\left(x_{n}\right)$ converges to $x$, then $x_{n} \preceq x$ for each $n \geqslant 1$. Besides if for all $x, y \in X$, there exists $z \in X$ which is comparable to $x$ and $\mathrm{y}$, then $\mathrm{T}$ has a unique fixed point.

\section{Main result}

In this section, we present and prove some lemmas that will be used in the sequel.

Lemma 2.1. Let $(X, d)$ be a quasi metric space equipped with an $m \omega$-distance $p$. Let $\left(x_{n}\right)$ be a sequence in $X$ and $\left(\alpha_{n}\right),\left(\beta_{n}\right)$ be sequences in $[0, \infty)$ converging to zero and let $\left(x_{n}\right)$ be a sequence in $X$. Then we have the following:

(1) If $\mathrm{p}\left(\mathrm{x}_{\mathrm{n}}, \mathrm{x}_{\mathrm{m}}\right) \leqslant \alpha_{\mathrm{n}}$ for any $\mathrm{m}, \mathrm{n} \in \mathbb{N}$ with $\mathrm{m} \geqslant \mathrm{n}$, then $\left(\mathrm{x}_{\mathrm{n}}\right)$ is a right Cauchy sequence in $(\mathrm{X}, \mathrm{d})$.

(2) If $\mathrm{p}\left(\mathrm{x}_{\mathrm{n}}, \mathrm{x}_{\mathrm{m}}\right) \leqslant \beta_{\mathrm{m}}$ for any $\mathrm{m}, \mathrm{n} \in \mathbb{N}$ with $\mathrm{n} \geqslant \mathrm{m}$, then $\left(\mathrm{x}_{\mathrm{n}}\right)$ is a left Cauchy sequence in $(\mathrm{X}, \mathrm{d})$.

Proof.

(1) Assume that $p\left(x_{n}, x_{m}\right) \leqslant \alpha_{n}, m \geqslant n$. Then for each $\epsilon>0$ we can find $N \in \mathbb{N}$ such that $p\left(x_{n}, x_{n+1}\right) \leqslant$ $\alpha_{n} \leqslant \frac{\epsilon}{2}$ and $p\left(x_{n+1}, x_{m}\right) \leqslant \alpha_{n+1} \leqslant \frac{\epsilon}{2}$, for all $m>n \geqslant N$. Thus by the definition of $m \omega$-distance we have $d\left(x_{n}, x_{m}\right) \leqslant \epsilon$ for all $m \geqslant n \geqslant N$. Hence $\left(x_{n}\right)$ is right Cauchy sequence.

(2) Assume that $p\left(x_{n}, x_{m}\right) \leqslant \beta_{m}, n \geqslant m$. Then for each $\epsilon>0$, we can find $N \in \mathbb{N}$ such that $p\left(x_{n}, x_{n-1}\right) \leqslant$ $\beta_{n-1} \leqslant \frac{\epsilon}{2}$ and $p\left(x_{n-1}, x_{m}\right) \leqslant \beta_{m} \leqslant \frac{\epsilon}{2}$, for all $n>m \geqslant N$. Thus by the definition of $m \omega$-distance, we have $d\left(x_{n}, x_{m}\right) \leqslant \epsilon$, for all $n \geqslant m \geqslant N$. Hence $\left(x_{n}\right)$ is left Cauchy sequence.

Remark 2.2. The above lemma implies that if $\lim _{n, m \rightarrow \infty} p\left(x_{n}, x_{m}\right)=0$, then $\left(x_{n}\right)$ is a Cauchy sequence in $(X, d)$. 
Lemma 2.3. Let $(\mathrm{X}, \mathrm{d})$ be a quasi metric space equipped with an $\mathrm{m} \omega$-distance $\mathrm{p}$. Let $\left(\mathrm{x}_{\mathrm{n}}\right)$ be a sequence in $\mathrm{X}$ such that

$$
\lim _{n \rightarrow \infty} p\left(x_{n}, x_{n+1}\right)=\lim _{n \rightarrow \infty} p\left(x_{n+1}, x_{n}\right)=0 .
$$

If $\left(x_{n}\right)$ is not a Cauchy sequence, then there exist $\epsilon>0$ and two sequences $\left(n_{k}\right)$ and $\left(m_{k}\right)$ of natural numbers such that

$$
\lim _{k \rightarrow \infty} p\left(x_{n_{k}}, x_{m_{k}}\right)=\lim _{k \rightarrow \infty} p\left(x_{n_{k}+1}, x_{m_{k}+1}\right)=\epsilon .
$$

Proof. Suppose that $\left(x_{n}\right)$ is not a Cauchy sequence. Without loss of generality, we assume that $\left(x_{n}\right)$ is not a right Cauchy sequence. Then there exist $\epsilon>0$ and two subsequences $\left(n_{k}\right)$ and $\left(m_{k}\right)$ of the natural numbers such that

$$
p\left(x_{n_{k}}, x_{m_{k}}\right) \geqslant \epsilon, \quad m_{k} \geqslant n_{k}
$$

where $m_{k}$ is chosen as the smallest index satisfying (2.2). This means that

$$
p\left(x_{n_{k}}, x_{m_{k}-1}\right)<\epsilon .
$$

From (2.2), we have

$$
\epsilon \leqslant p\left(x_{n_{k}}, x_{m_{k}}\right) \leqslant p\left(x_{n_{k}}, x_{m_{k}-1}\right)+p\left(x_{m_{k}-1}, x_{m_{k}}\right)<\epsilon+p\left(x_{m_{k}-1}, x_{m_{k}}\right) .
$$

Taking the limit as $k \rightarrow \infty$ and using (2.1), we get

$$
\lim _{k \rightarrow \infty} p\left(x_{n_{k}}, x_{m_{k}}\right)=\epsilon .
$$

Also,

$$
\begin{aligned}
p\left(x_{n_{k}}, x_{m_{k}}\right)-p\left(x_{n_{k}}, x_{n_{k}+1}\right)-p\left(x_{m_{k}+1}, x_{m_{k}}\right) & \leqslant p\left(x_{n_{k}+1}, x_{m_{k}+1}\right) \\
& \leqslant p\left(x_{n_{k}+1}, x_{n_{k}}\right)+p\left(x_{n_{k}}, x_{m_{k}}\right)+p\left(x_{m_{k}}, x_{m_{k}+1}\right) .
\end{aligned}
$$

Let $k$ go to infinity and using (2.1) and (2.3), we reach

$$
\lim _{k \rightarrow \infty} p\left(x_{n_{k}+1}, x_{m_{k}+1}\right)=\epsilon .
$$

In order to facilitate our work, we introduce the following definition.

Definition 2.4. Let $(X, d)$ be a quasi metric space equipped with mw-distance $p$. A self-mapping $T: X \rightarrow X$ is called $(\varphi, \alpha)$-Geraghty contraction if there exist $\varphi \in \Psi$ and $\alpha \in S$ such that

$$
\varphi p(T x, T y) \leqslant \alpha(p(x, y)) \varphi p(x, y), \quad \forall x, y \in X .
$$

In the next theorem, we prove a fixed point result of Geraghty's type contraction condition in a complete quasi metric space through modified $\omega$-distance mappings.

Theorem 2.5. Let $(\mathrm{X}, \mathrm{d})$ be a complete quasi metric space and $p$ be an mw-distance on $\mathrm{X}$ and $\mathrm{T}: \mathrm{X} \rightarrow \mathrm{X}$ be a $(\varphi, \alpha)$-Geraghty mapping. Assume that one of the following conditions holds true:

(1) If $u \neq T u$, then $\inf \{p(x, u)+p(T x, u): x \in X\}>0$.

(2) $\mathrm{T}$ is continuous.

Then Thas a unique fixed point.

Proof. Let $x_{0} \in X$. Define a sequence $x_{n}=T x_{n-1}, n \in \mathbb{N}$. Consider $n \in \mathbb{N}$. From the contractive condition, we have

$$
\begin{aligned}
\varphi p\left(x_{n}, x_{n+1}\right) & =\varphi p\left(T x_{n-1}, T x_{n}\right) \\
& \leqslant \alpha\left(p\left(x_{n-1}, x_{n}\right)\right) \varphi p\left(x_{n-1}, x_{n}\right) .
\end{aligned}
$$

Since $\alpha(t)<1$ for all $t \geqslant 0$, then $\varphi p\left(x_{n}, x_{n+1}\right)<\varphi p\left(x_{n-1}, x_{n}\right)$. As $\varphi$ is nondecreasing, we have 
$p\left(x_{n}, x_{n+1}\right)<p\left(x_{n-1}, x_{n}\right)$. Thus the sequence $\left(p\left(x_{n}, x_{n+1}\right): n \in \mathbb{N}\right)$ is a nonnegative decreasing sequence. Hence there is $r \geqslant 0$ such that $\lim _{n \rightarrow \infty} p\left(x_{n}, x_{n+1}\right)=r$. Suppose that $r>0$. By (2.4), we have

$$
\frac{\varphi p\left(x_{n}, x_{n+1}\right)}{\varphi p\left(x_{n-1}, x_{n}\right)} \leqslant \alpha\left(p\left(x_{n-1}, x_{n}\right)\right)
$$

By taking the limit as $n \rightarrow \infty$ we get $\lim _{n \rightarrow \infty} \alpha\left(p\left(x_{n-1}, x_{n}\right)\right)=1$. Since $\alpha \in S$, then $r=0$ a contradiction. So,

$$
\lim _{n \rightarrow \infty} p\left(x_{n}, x_{n+1}\right)=0 .
$$

Similarly, we can show that

$$
\lim _{n \rightarrow \infty} p\left(x_{n+1}, x_{n}\right)=0 .
$$

Now, our claim is to show that $\left(x_{n}\right)$ is a Cauchy sequence in $(X, d)$. Assume to the contrary that $\left(x_{n}\right)$ is not a Cauchy sequence. Due to Lemma 2.3, there exist $\epsilon>0$ and two sequences $\left(n_{k}\right)$ and $\left(m_{k}\right)$ of natural numbers such that

$$
\lim _{k \rightarrow \infty} p\left(x_{n_{k}}, x_{m_{k}}\right)=\lim _{k \rightarrow \infty} p\left(x_{n_{k}+1}, x_{m_{k}+1}\right)=\epsilon .
$$

Substitute $x=x_{n_{k}}$ and $y=x_{m_{k}}$ in the contractive condition, we obtain that

$$
\begin{aligned}
\varphi p\left(x_{n_{k}+1}, x_{m_{k}+1}\right) & =\varphi p\left(T x_{n_{k}}, T x_{m_{k}}\right) \\
& \leqslant \alpha\left(p\left(x_{n_{k}}, x_{m_{k}}\right)\right) \varphi p\left(x_{n_{k}}, x_{m_{k}}\right) .
\end{aligned}
$$

Therefore,

$$
\frac{\varphi p\left(x_{n_{k}+1}, x_{m_{k}+1}\right)}{\varphi p\left(x_{n_{k}}, x_{m_{k}}\right)} \leqslant \alpha\left(p\left(x_{n_{k}}, x_{m_{k}}\right)\right) .
$$

Taking the limit as $k \rightarrow \infty$, we deduce $\lim _{k \rightarrow \infty} \alpha\left(p\left(x_{n_{k}}, x_{m_{k}}\right)\right)=1$ and so $\lim _{k \rightarrow \infty} p\left(x_{n_{k}}, x_{m_{k}}\right)=0$ a contradiction since $\epsilon>0$. Hence $\left(x_{n}\right)$ is a Cauchy sequence. Thus there is $u \in X$ such that $\left(x_{n}\right)$ converges to u. Since $\lim _{n, m \rightarrow \infty} p\left(x_{n}, x_{m}\right)=0$, then for a given $\epsilon>0$ there is $k \in \mathbb{N}$ such that $p\left(x_{n}, x_{m}\right) \leqslant \frac{\epsilon}{2}$, for all $n, m \geqslant k$. By the lower semi continuity of $p$ we have

$$
p\left(x_{n}, u\right) \leqslant \lim _{l \rightarrow \infty} \inf p\left(x_{n}, x_{l}\right) \leqslant \frac{\epsilon}{2}, \quad \forall n \geqslant k .
$$

Now, assume that (1) holds true if $u \neq T u$, then

$$
\begin{aligned}
\inf \{p(x, u)+p(T x, u): x \in X\} & \leqslant \inf \left\{p\left(x_{n}, u\right)+p\left(T x_{n}, u\right): n \in \mathbb{N}\right\} \\
& =\inf \left\{p\left(x_{n}, u\right)+p\left(x_{n+1}, u\right): n \in \mathbb{N}\right\} \\
& \leqslant \epsilon
\end{aligned}
$$

for all $\epsilon>0$ a contradiction. Hence $T u=u$.

If (2) holds, then the continuity of $T$ implies that $T u=u$. have

To prove the uniqueness, assume that there is $v \in X$ such that $T v=v$. By the contractive condition, we

$$
\begin{aligned}
\varphi p(u, v) & =\varphi p(T u, T v) \\
& \leqslant \alpha(p(u, v)) \varphi p(u, v) .
\end{aligned}
$$

As $\alpha \in S$, we have $\varphi p(u, v)=0$ and so $p(u, v)=0$. 
Also,

$$
\begin{aligned}
\varphi p(u, u) & =\varphi p(T u, T u) \\
& \leqslant \alpha(p(u, u)) \varphi p(u, u) .
\end{aligned}
$$

Following the same argument, we obtain $p(u, u)=0$. Therefore by $(\mathrm{mW} 3)$ of the definition of $m \omega$ distance, we get $u=v$.

Theorem 2.6. Let $(\mathrm{X}, \mathrm{d})$ be a complete quasi metric space and $\mathrm{p}$ be a strong $\mathrm{m} \omega$-distance on $\mathrm{X}$ and $\mathrm{T}: \mathrm{X} \rightarrow \mathrm{X}$ be $a(\varphi, \alpha)$-Geraghty mapping. Then $\mathrm{T}$ has a unique fixed point.

Proof. Following the proof of Theorem 2.5 step by step, we can show that $\lim _{n, m \rightarrow \infty} p\left(x_{n}, x_{m}\right)=0$. So $\left(x_{n}\right)$ is a Cauchy sequence in the complete quasi metric space $(X, d)$. Thus there is $u \in X$ such that $\left(x_{n}\right)$ converges to $u$.

Given $\epsilon>0$. Since $\lim _{n, m \rightarrow \infty} p\left(x_{n}, x_{m}\right)=0$, then there is $N \in \mathbb{N}$ such that $p\left(x_{n}, x_{m}\right) \leqslant \epsilon$, for all $n, m \geqslant N$. So, by the lower semi continuity of $p$ (W2) and (mW2), we have

$$
\begin{aligned}
& p\left(x_{n}, u\right) \leqslant \lim _{j \rightarrow \infty} \inf p\left(x_{n}, x_{j}\right) \leqslant \epsilon, \quad \forall n \geqslant N, \\
& p\left(u, x_{n}\right) \leqslant \lim _{l \rightarrow \infty} \inf p\left(x_{l}, x_{n}\right) \leqslant \epsilon, \quad \forall n \geqslant N .
\end{aligned}
$$

Now, the contraction condition yields:

$$
\begin{aligned}
\varphi p\left(T u, x_{n+1}\right) & =\varphi p\left(T u, T x_{n}\right) \\
& \leqslant \alpha\left(p\left(u, x_{n}\right)\right) \varphi p\left(u, x_{n}\right) .
\end{aligned}
$$

Since $\alpha(t)<1$ for all $t \geqslant 0$ and $\varphi$ is nondecreasing, then $p\left(T u, x_{n+1}\right)<p\left(u, x_{n}\right)$. Hence, $p\left(T u, x_{n+1}\right)<\epsilon$, for all $n \geqslant N$. Thus, by (mW3) of the definition of $m \omega$-distance, we have $d(T u, u)=0$ and so $T u=u$. The proof of the uniqueness is the same as of the proof of Theorem 2.5.

Definition 2.7. Let $\Phi$ be the set of all continuous functions $\phi:[0, \infty) \rightarrow[0, \infty)$ such that the following properties are satisfied:

(1) $\phi(t)<t, \forall t \in(0, \infty)$;

(2) $\phi(t)=0$ if and only if $t=0$.

Definition 2.8. Let $(X, d)$ be a quasi metric space equipped with m $\omega$-distance $p$. A self-mapping $T: X \rightarrow X$ is called $(\lambda, \phi)$-Kannan contraction if there are $\lambda \in\left[0, \frac{1}{2}\right)$ and $\phi \in \Phi$ such that

$$
p(T x, T y) \leqslant \lambda[\phi p(x, T x)+\phi p(y, T y)], \quad \forall x, y \in X
$$

Next, we move on to study some fixed point results of $(\lambda, \phi)$-Kannan type contractions.

Theorem 2.9. Let $(\mathrm{X}, \mathrm{d})$ be a complete quasi metric space and $\mathrm{p}$ be an mw-distance on $\mathrm{X}$ and $\mathrm{T}: \mathrm{X} \rightarrow \mathrm{X}$ be $(\lambda, \phi)$-Kannan contraction. Assume that one of the following conditions holds true:

(1) If $u \neq T u$, then $\inf \{p(x, u)+p(T x, u): x \in X\}>0$.

(2) $T$ is continuous.

Then $\mathrm{T}$ has a unique fixed point.

Proof. Let $x_{0} \in X$ and define a sequence $x_{n}=T x_{n-1}, n \in \mathbb{N}$.

Let $n \in \mathbb{N}$. From the contractive condition, we have

$$
\begin{aligned}
p\left(x_{n}, x_{n+1}\right) & =p\left(T x_{n-1}, T x_{n}\right) \\
& \leqslant \lambda\left[\phi p\left(x_{n-1}, x_{n}\right)+\phi p\left(x_{n}, x_{n+1}\right)\right] \\
& <\lambda\left[p\left(x_{n-1}, x_{n}\right)+p\left(x_{n}, x_{n+1}\right)\right] .
\end{aligned}
$$

Thus, 


$$
p\left(x_{n}, x_{n+1}\right)<\frac{\lambda}{1-\lambda} p\left(x_{n-1}, x_{n}\right) .
$$

Since $\frac{\lambda}{1-\lambda}<1$, the sequence $\left(p\left(x_{n}, x_{n+1}\right): n \in \mathbb{N}\right)$ is a nonnegative decreasing sequence. Hence there is $r \geqslant 0$ such that $\lim _{n \rightarrow \infty} p\left(x_{n}, x_{n+1}\right)=r$. From (2.5), we have

$$
p\left(x_{n}, x_{n+1}\right) \leqslant \lambda\left[\phi p\left(x_{n-1}, x_{n}\right)+\phi p\left(x_{n}, x_{n+1}\right)\right] .
$$

By taking the limit as $n \rightarrow \infty$ we get $r \leqslant \lambda[\phi(r)+\phi(r)]=2 \lambda \phi(r)<\phi(r)$. Thus $\phi(r)=0$. Therefore,

$$
\lim _{n \rightarrow \infty} p\left(x_{n}, x_{n+1}\right)=0 \text {. }
$$

Also, we obtain

$$
\lim _{n \rightarrow \infty} p\left(x_{n+1}, x_{n}\right)=0 .
$$

Due to Lemma 2.3, if $\left(x_{n}\right)$ is not a Cauchy sequence, then there exist $\epsilon>0$ and two sequences $\left(n_{k}\right)$ and $\left(m_{k}\right)$ of natural numbers such that

$$
\lim _{k \rightarrow \infty} p\left(x_{n_{k}}, x_{m_{k}}\right)=\lim _{k \rightarrow \infty} p\left(x_{n_{k}+1}, x_{m_{k}+1}\right)=\epsilon .
$$

By substituting $x=x_{n_{k}}$ and $y=x_{m_{k}}$ in the contractive condition, we obtain that

$$
\begin{aligned}
p\left(x_{n_{k}+1}, x_{m_{k}+1}\right) & =p\left(T x_{n_{k}}, T x_{m_{k}}\right) \\
& \leqslant \lambda\left[\phi p\left(x_{n_{k}}, x_{n_{k}+1}\right)+\phi p\left(x_{m_{k}}, x_{m_{k}+1}\right)\right] .
\end{aligned}
$$

Taking the limit as $k \rightarrow \infty$, we get $\epsilon \leqslant \lambda[0+0]=0$ a contradiction, because $\epsilon>0$. Hence $\left(x_{n}\right)$ is a Cauchy sequence. Therefore, there is $z \in X$ such that $\left(x_{n}\right)$ converges to $z$.

Since $\lim _{n, m \rightarrow \infty} p\left(x_{n}, x_{m}\right)=0$, then for each $\epsilon>0$ there is $N \in \mathbb{N}$ such that

$$
p\left(x_{n}, x_{m}\right) \leqslant \epsilon, \quad \forall n, m \geqslant N .
$$

By the lower semi continuity of $p$, we have

$$
p\left(x_{n}, z\right) \leqslant \lim _{l \rightarrow \infty} \inf p\left(x_{n}, x_{l}\right) \leqslant \epsilon, \quad \forall n \geqslant N .
$$

Now, assume that (1) holds true if $z \neq T z$, then

$$
\begin{aligned}
\inf \{p(x, z)+p(T x, z): x \in X\} & \leqslant \inf \left\{p\left(x_{n}, z\right)+p\left(T x_{n}, z\right): n \in \mathbb{N}\right\} \\
& =\inf \left\{p\left(x_{n}, z\right)+p\left(x_{n+1}, z\right): n \in \mathbb{N}\right\} \\
& \leqslant 2 \epsilon
\end{aligned}
$$

for each $\epsilon>0$ a contradiction. Hence $T z=z$.

Also, if (2) holds, then the continuity of $\mathrm{T}$ implies that $\mathrm{T} z=z$.

To prove the uniqueness, first we show that for $x \in X$ if $T x=x$, then $p(x, x)=0$.

Assume $p(x, x)>0$. The contractive condition yields

$$
\begin{aligned}
p(x, x)=p(T x, T x) & \leqslant \lambda[\phi p(x, x)+\phi p(x, x)] \\
& <\lambda[p(x, x)+p(x, x)] \\
& <p(x, x),
\end{aligned}
$$

a contradiction. Thus $p(x, x)=0$.

Now, assume that there is $v \in \mathrm{X}$ such that $\mathrm{T} v=v$. By the contractive condition, we have

$$
\begin{aligned}
p(v, z)=p(T v, T z) & \leqslant \lambda[\phi p(v, T v)+\phi p(z, T z)] \\
& =\lambda[\phi p(v, v)+\phi p(z, z)] \\
& =0
\end{aligned}
$$

Therefore, by (mW3) of the definition of mw-distance, we have $u=v$. 


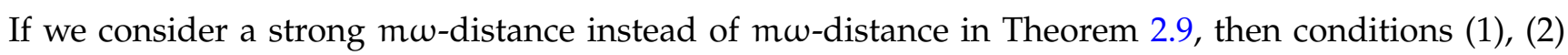
can be dropped.

Theorem 2.10. Let $(\mathrm{X}, \mathrm{d})$ be a complete quasi metric space and $p$ be a strong $\mathrm{m} \omega$-distance on $\mathrm{X}$. Assume that $\mathrm{T}: \mathrm{X} \rightarrow \mathrm{X}$ is a $(\lambda, \phi)$-Kannan contraction. Then $\mathrm{T}$ has a unique fixed point.

Proof. Following the proof of Theorem 2.9 step by step, we can show that $\lim _{n, m \rightarrow \infty} p\left(x_{n}, x_{m}\right)=0$. So $\left(x_{n}\right)$ is a Cauchy sequence in the complete quasi metric space $(X, d)$. Thus there is $z \in X$ such that $\left(x_{n}\right)$ converges to $z$.

Given $\epsilon>0$. Since $\lim _{n, m \rightarrow \infty} p\left(x_{n}, x_{m}\right)=0$, then there is $N_{1} \in \mathbb{N}$ such that $p\left(x_{n}, x_{m}\right) \leqslant \frac{\epsilon}{2}$, for all $n, m \geqslant N_{1}$. Thus,

$$
p\left(x_{n}, x_{n+1}\right) \leqslant \frac{\epsilon}{2}, \quad \forall n \geqslant N_{1} .
$$

Also, by the lower semi continuity of $p,(\mathrm{~mW} 2)$, we have

$$
p\left(z, x_{n}\right) \leqslant \lim _{l \rightarrow \infty} \inf p\left(x_{l}, x_{n}\right) \leqslant \frac{\epsilon}{2}, \quad \forall n \geqslant N_{1} .
$$

By the triangle inequality, we get

$$
\begin{aligned}
p(z, T z) & \leqslant p\left(z, x_{n+1}\right)+p\left(x_{n+1}, T z\right) \\
& \leqslant p\left(z, x_{n+1}\right)+\lambda\left[\phi p\left(x_{n}, x_{n+1}\right)+\phi p(z, T z)\right] \\
& <p\left(z, x_{n+1}\right)+\lambda p\left(x_{n}, x_{n+1}\right)+\lambda p(z, T z) .
\end{aligned}
$$

Hence

$$
p(z, T z)<\frac{1}{1-\lambda} p\left(z, x_{n+1}\right)+\frac{\lambda}{1-\lambda} p\left(x_{n}, x_{n+1}\right) .
$$

Now, the contraction condition yields:

$$
\begin{aligned}
p\left(x_{n+1}, T z\right)=p\left(T x_{n}, T z\right) & \leqslant \lambda\left[\phi p\left(x_{n}, x_{n+1}\right)+\phi p(z, T z)\right] \\
& <\lambda p\left(x_{n}, x_{n+1}\right)+\lambda p(z, T z) \\
& <\lambda p\left(x_{n}, x_{n+1}\right)+\frac{\lambda}{1-\lambda} p\left(z, x_{n+1}\right)+\frac{\lambda^{2}}{1-\lambda} p\left(x_{n}, x_{n+1}\right) \\
& =\frac{\lambda}{1-\lambda}\left[p\left(x_{n}, x_{n+1}\right)+p\left(z, x_{n+1}\right)\right] \\
& <p\left(x_{n}, x_{n+1}\right)+p\left(z, x_{n+1}\right)
\end{aligned}
$$

Hence, by (2.6) and (2.7), we have

$$
\mathrm{p}\left(\mathrm{x}_{\mathrm{n}+1}, \mathrm{~T} z\right)<\frac{\epsilon}{2}+\frac{\epsilon}{2}=\epsilon, \quad \forall \mathrm{n} \geqslant \mathrm{N}_{1} .
$$

Therefore, by (mW3) of the definition of mw-distance, we have $\mathrm{d}(z, \mathrm{~T} z)=0$ and so $z=\mathrm{T} z$. The proof of the uniqueness is the same as in the proof of Theorem 2.9.

Let $\phi:[0, \infty) \rightarrow[0, \infty)$ be defined by $\phi(t)=k t, k \in(0,1)$ and use Theorems 2.9-2.10. Then we get the following results.

Corollary 2.11. Let $(X, d)$ be a complete quasi metric space and $p$ be an mw-distance on $X$. Let $\mathrm{k} \in\left(0, \frac{1}{2}\right)$ and $\mathrm{T}: \mathrm{X} \rightarrow \mathrm{X}$ be a self-mapping such that

$$
p(T x, T y) \leqslant k[p(x, T x)+p(y, T y)], \quad \forall x, y \in X .
$$

Also, assume that one of the following conditions holds true: 
(1) If $u \neq T u$, then $\inf \{p(x, u)+p(T x, u): x \in X\}>0$.

(2) $\mathrm{T}$ is continuous.

Then T has a unique fixed point.

Corollary 2.12. Let $(\mathrm{X}, \mathrm{d})$ be a complete quasi metric space and $\mathrm{p}$ be a strong mw-distance on $\mathrm{X}$. Let $\mathrm{k} \in\left(0, \frac{1}{2}\right)$ and $\mathrm{T}: \mathrm{X} \rightarrow \mathrm{X}$ be a self-mapping satisfying the following condition

$$
p(T x, T y) \leqslant k[p(x, T x)+p(y, T y)], \quad \forall x, y \in X .
$$

Then T has a unique fixed point.

\section{Acknowledgment}

The authors thank the reviewer for his/her valuable report that helped us to rewrite our paper in a nice way.

\section{References}

[1] K. Abodayeh, A. Bataihah, W. Shatanawi, Generalized $\Omega$-distance mappings and some fixed point theorems, Politehn. Univ. Bucharest Sci. Bull. Ser. A Appl. Math. Phys., 79 (2017), 223-232. 1

[2] K. Abodayeh, W. Shatanawi, A. Bataihah, Fixed point theorem through $\Omega$-distance of Suzuki type conraction condition, G. U. J. Sci., 29 (2016), 129-133.

[3] K. Abodayeh, W. Shatanawi, A. Bataihah, A. H. Ansari, Some fixed point and common fixed point results through $\Omega$-distance under nonlinear contractions, G. U. J. Sci., 30 (2017), 293-302.

[4] I. Abu-Irwaq, I. Nuseir, A. Bataihah, Common Fixed Point Theorems in G-metric Spaces with $\Omega$-distance, J. Math. Anal., 8 (2017), 120-129. 1

[5] C. Alegre, J. Marin, Modified $\omega$-distance on quasi metric spaces and fixed point theorem on complete quasi metric spaces, Topol. Appl., 203 (2016), 32-41. 1, 1.6, 1.7, 1.8, 1

[6] A. Amini-Harandi, H. Emami, A fixed point theorem for contraction type maps in partially ordered metric spaces and application to ordinary differential equations, Nonlinear Anal., 72 (2010), 2238-2242. 1.12

[7] V. Berinde, Generalized coupled fixed point theorems for mixed monotone mappings in partially ordered metric spaces, Nonlinear Anal., 74 (2011), 7347-7355. 1

[8] V. Berinde, Coupled fixed point theorems for $\Phi$-contractive mixed monotone mappings in partially ordered metric spaces, Nonlinear Anal., 75 (2012), 3218-3228.

[9] A. Branciari, A fixed point theorem for mapping satisfying a general contractive condition of integral type, Int. J. Math. Math. Sci., 29 (2002), 531-536.

[10] B. S. Choudhury, A. Kundu, A coupled coincidence point result in partially ordered metric spaces for compatible mappings, Nonlinear Anal., 73 (2010), 2524-2531.

[11] L. B. Ćirić, A generalization of Banch's contraction principle, Proc. Amer. Math. Soc., 45 (1974), 267-273. 1

[12] M. A. Geraghty, On contractive mappings, Proc. Amer. Math. Soc., 40 (1973), 604-608. 1.10, 1

[13] M. Jleli, B. Samet, Remarks on G-metric spaces and fixed point theorems, Fixed Point Theory Appl., 2012 (2012), 7 pages. 1.2, 1.3, 1.4, 1.5

[14] R. Kannan, Some results on fixed points, Bull. Calcutta Math. Soc., 60 (1968), 71-76. 1

[15] M. S. Khan, M. Swaleh, S. Sessa, fixed point theorems by altering distances between the points, Bull. Austral. Math. Soc., 30 (1984), 1-9. 1.9

[16] M. Kikkawa, T. Suzuki, Three fixed point theorems for generalized contractions with constants in complete metric spaces, Nonlinear Anal., 69 (2008), 2942-2949. 1

[17] W. Shatanawi, G. Maniu, A. Bataihah, F. Bani Ahmad, Common fixed points for mappings of cyclic form satisfying linear contractive conditions with Omega-distance, Politehn. Univ. Bucharest Sci. Bull. Ser. A Appl. Math. Phys., 79 (2017), 11-20.

[18] W. Shatanawi, M. S. Noorani, H. Alsamir, A. Bataihah, Fixed and common fixed point theorems in partially ordered quasi-metric spaces, J. Math. Computer Sci., 16 (2016), 516-528.

[19] W. Shatanawi, A. Pitea, Some coupled fixed point theorems in quasi partial-metric spaces, Fixed Point Theory Appl., 2013 (2013), 15 pages. 1

[20] P. V. Subrahmanyam, Completeness and fixed points, Monatsh. Math., 80 (1975), 325-330. 1

[21] T. Suzuki, A generalized Banach contraction principle that characterizes metric completeness, Proc. Amer. Math. Soc., 136 (2008), 1861-1869. 1

[22] W. A. Wilson, On quasi-metric spaces, Amer. J. Math., 53 (1931), 675-684. 1, 1.1 